\title{
Reactions of 5-Bromo Substituted Pyrimidine Nucleosides with Aqueous Alkalies: Kinetics and Mechanisms*
}

\author{
Rainer Käppi and Harri Lönnberg \\ Department of Chemistry and Biochemistry, University of Turku, SF-20500 Turku, Finland
}

\begin{abstract}
Käppi, Rainer and Lönnberg, Harri, 1986. Reactions of 5-Bromo Substituted Pyrimidine Nucleosides with Aqueous Alkalies: Kinetics and Mechanisms. - Acta Chem. Scand. B 40: 768-775.
\end{abstract}

Kinetics for the parallel and consecutive steps of the reactions of 5-bromocytidine, 5-bromouridine and its $5^{\prime}-O$-methyl and $2^{\prime}, 3^{\prime}-O$-isopropylidene derivatives with aqueous alkalies were studied by LC. The mechanisms of the partial reactions involved are discussed.

The early observations ${ }^{2-4}$ that some 5-halo substituted pyrimidine nucleosides exhibit antiviral properties have stimulated the research of their stability in aqueous solutions. Owing to the electron attracting nature of the halogen substituent, 5-halopyrimidine nucleosides are considerably more susceptible to the action of nucleophiles than their unsubstituted counterparts. For example, reactions with aqueous alkalies generally involve several parallel and consecutive steps, yielding complicated product mixtures, the com-<smiles>[X]c1cn(C2OC(O)C(O)C2[Y])c(=O)[nH]c1=O</smiles>

$1 a: X=B r, Y=O H$

1b: $X=\mathrm{I}, \mathrm{Y}=\mathrm{OH}$ 1c: $X=I, Y=H$

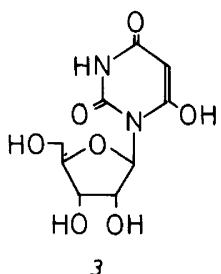

${ }^{*}$ Part XIX of a series. See Ref. 1.

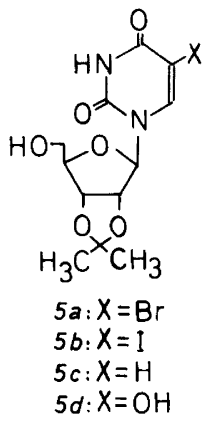<smiles>CC(C)(C)OC1OC2C(O)OC1C2N1C(O)CC(=O)NC1O</smiles><smiles>CNC(CN1C2OC(O)C3C2OC1C3OC(C)(C)C)C(=O)O</smiles>

positions of which depend on the experimental conditions employed. Kinetic studies with 5-halouridines $(1 a, b)$ have led to the conclusion that the halogen substituent is displaced by hydroxide ion at low base concentrations, while at high alkalinities, the attack on C6 prevails. ${ }^{5}$ The 5 - and 6-hydroxyuridines $(2 a, 3)$ formed are finally degraded to nonchromophoric products. The hydrolysis of 2'-deoxy-5-iodouridine (1c) has been shown to proceed by intermediary formations of 2 '-deoxy-5-hydroxyuridine $(2 b)$ and 2 '-deoxyuri- 

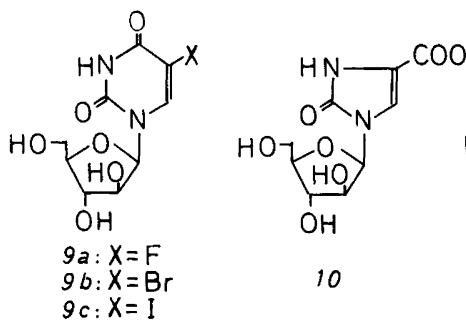

10

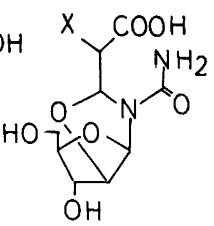

11 $a: X=F$

$11 b: X=B r$

$11 c: X=I$

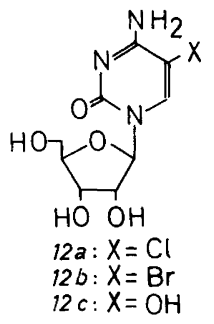

dine (4), the route via the former compound being favoured. ${ }^{6} \mathrm{~A}$ direct fragmentation of the starting material to nonchromophoric compounds competes with the formation of $2 a, 2 b$ and $3 .{ }^{5,6}$ In contrast, 5-halo- $2^{\prime}, 3^{\prime}-O$-isopropylideneuridines $(5 a, b)$ have been reported to yield more complicated product mixtures which consist of the $2^{\prime}, 3^{\prime}-O$-isopropylidene derivatives of uridine (5c), 5',6-anhydro-6-hydroxyuridine (6), 5hydroxyuridine (7), and 1-( $\beta$-D-ribofuranosyl)-2oxo-4-imidazoline-4-carboxylic acid (8) ${ }^{7,8}$

Arabinofuranosyl nucleosides of 5-halouracils $(9 a, b, c)$ are cleaved in aqueous alkali more readily than 5-halouridines. ${ }^{9-11}$ The main product is 1 ( $\beta$-D-arabinofuranosyl)-2-oxo-4-imidazoline-4carboxylic acid $(10)$, which is formed via an open chain 2',6-anhydro ureido intermediate (11$a, b, c)$. Among cytosine nucleosides, 5-chlorocytidine (12a) has been shown to undergo competitively a deamination to the corresponding uridine and a cleavage to an open chain ureido compound (13). ${ }^{12}$

Despite several reports on the products of the alkaline decomposition of 5-halopyrimidine nucleosides, little is known about the kinetics and mechanisms of the partial reactions involved. The aim of the present study was to clarify these subjects by performing a detailed kinetic analysis of the reactions of 5-bromocytidine (12b) and 5- bromouridine $(1 a)$ with aqueous alkalies. Comparative kinetic studies with $5^{\prime}-O$-methyl and 2', $3^{\prime}-O$-isopropylidene derivatives of $1 a$ were used to further the understanding of the reaction mechanisms.

\section{Results and discussion}

LC analyses of the aliquots withdrawn at different intervals from aqueous sodium hydroxide solutions of 5-bromocytidine $(12 b)$ indicated that the disappearance of the starting material was accompanied by the formation of two products which were chromatographically identical with authentic samples of 5-hydroxycytidine (12c) and 5-bromouridine (1a). Preparative fractionation on a reversed phase column and characterization of the products by ${ }^{13} \mathrm{C}$ NMR spectroscopy verified their formation. Separate kinetic runs with these compounds showed that $12 c$ was converted directly to nonchromophoric compounds, whereas $1 a$ gave several UV absorbing products, the structures of which are described below. Accordingly, the reactions of $12 b$ with aqueous alkalies may be depicted by Scheme 1. An example of the time-dependent product distribution is presented in Fig. 1.

The rate constants obtained for the different partial reactions involved in Scheme 1 are listed

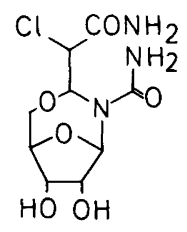

13<smiles>O=c1cc2n(c(=O)[nH]1)C1OC(O2)C(O)C1O</smiles>

14

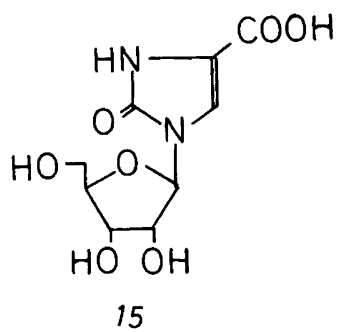

15 


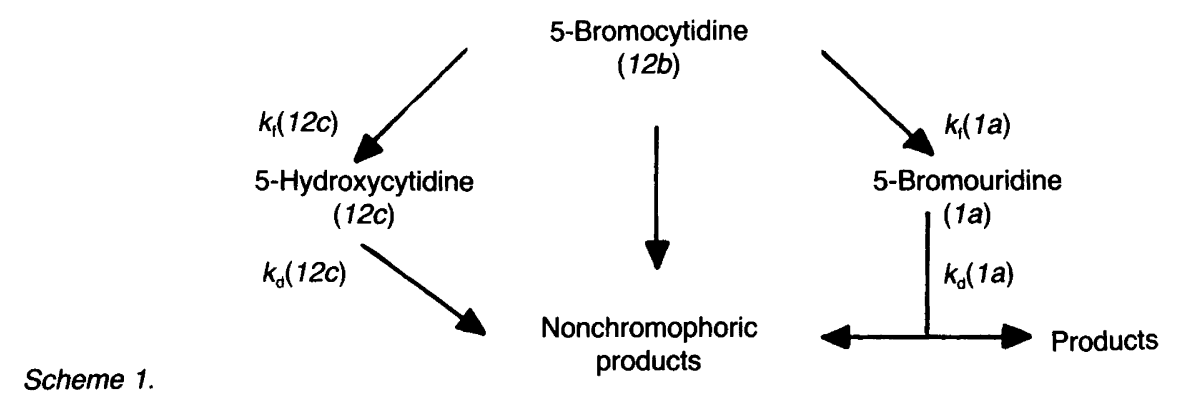

in Table 1 . The data clearly show that the formation of $1 a$ and $12 c$ comprises less than $60 \%$ of the disappearance of the starting material. Obviously a direct fragmentation to nonchromophoric compounds competes with the deamination and dehalogenation of $12 b$. The deamination and dehalogenation are both of approximately first-order with respect to hydroxide ion, in accordance with mechanisms involving a rate-limiting nucleophilic attack of a hydroxide ion on the 5-bromocytosine ring. If an ionized ribosyl hydroxyl group would act as an intramolecular nucleophile, a curvilinear dependence of the first-order rate constants on $\left[\mathrm{OH}^{-}\right]$could be expected. For comparison, arabino- and lyxo-uridines, which are decomposed by an intramolecular attack of the $2^{\prime}$-oxyanion, exhibit such a behavior. ${ }^{13}$ The sites of the intermolecular attacks of hydroxide ion cannot be definitely deduced on the basis of the available data. Tentatively, one may assume that the attacks on $\mathrm{C} 4$ and $\mathrm{C} 5$ lead to the hydrolytic deamination and dehalogenation, respectively. The attack on $\mathrm{C} 4$ may also result in a rupture of the N3-C4 bond, and thus initiate the fragmentation to nonchromophoric products. A similar mechanism has been previously suggested for unsubstituted cytidine on the basis of the effects that methyl groups at C5, C6 and N4 exert on the rates of deamination and fragmentation. ${ }^{13}$ An initial attack on $\mathrm{C} 6$ is also possible, but appears less attractive, since it would be expected to give 6hydroxycytidine rather than 5-hydroxycytidine as the main dehalogenation product; 5-hydroxycytidine $(12 c)$ is probably degraded oxidatively to nonchromophoric products. As seen from Table 1 , the concentration of hydroxide ion has only a modest influence on the rate of its disappearance.

When followed by LC, the alkaline cleavage of 5-bromouridine (1a) was observed to proceed by an intermediary formation of four UV absorbing products that were chromatographically identical with authentic samples of 6-hydroxyuridine (3), 5-hydroxyuridine $(2 a), 5$ ', 6-anhydro-6-hydroxyuridine (14), and 1-( $\beta$-D-ribofuranosyl)-2-oxo-5imidazoline-4-carboxylic acid (15). The product composition was thus analogous to that reported for the corresponding $2^{\prime}, 3^{\prime}-O$-isopropylidene derivative $(5 a) .^{7.8}$ However, the formation of uridine was not observed. Fig. 2 shows the time-dependent appearance of the products. As seen, the mole fraction of each intermediate remains low during the course of the decomposition of $1 a$. The shapes of the curves suggest that $2 a, 3$ and 14 are formed directly from $1 a$, while the formation of 15 is preceded by an accumulation of a relatively stable intermediate.

Separate kinetic measurements with $2 a, 3,14$ and 15 indicated that 3 and 15 were degraded to nonchromophoric products without an appearance of any UV absorbing intermediate. With 14, a direct fragmentation to nonchromophoric com-

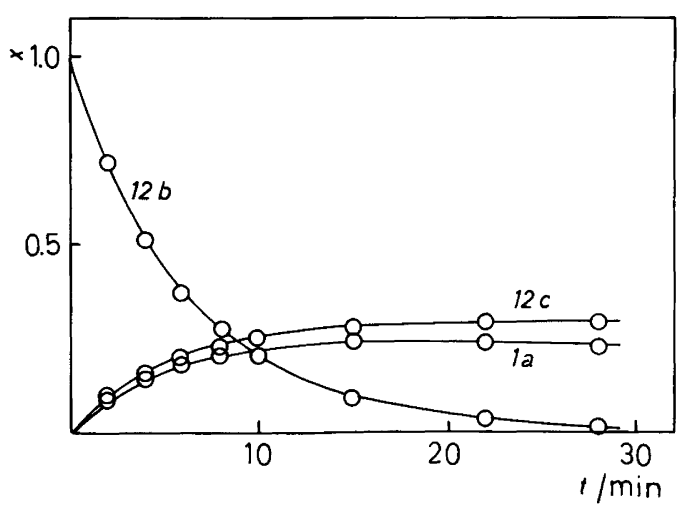

Fig. 1. Time-dependent product distribution for the decomposition of 5-bromocytidine (12b) in aqueous sodium hydroxide $\left(0.20 \mathrm{~mol} \mathrm{dm}^{-3}\right)$ at $363.2 \mathrm{~K}$. 
Table 1. The pseudo first-order rate constants for the partial reactions involved in the decomposition of 5bromocytidine (12b) in aqueous sodium hydroxide at $363.2 \mathrm{~K}$.

\begin{tabular}{llll}
\hline $\begin{array}{l}\text { Com- } \\
\text { pound }\end{array}$ & $\begin{array}{l}{\left[\mathrm{OH}^{-}\right] / \mathrm{mol}} \\
\mathrm{dm}^{-3}\end{array}$ & $\begin{array}{l}k_{\mathrm{f}}(\mathrm{i}) / 10^{-4} \\
\mathrm{~s}^{-1 a}\end{array}$ & $\begin{array}{l}k_{\mathrm{d}}(\mathrm{i}) / 10^{-4} \\
\mathrm{~s}^{-1 a}\end{array}$ \\
\hline $12 b$ & 0.20 & & $26.8(4)^{b}$ \\
& 0.15 & & $21.6(3)$ \\
& 0.10 & & $16.9(2)$ \\
& 0.050 & & $10.7(2)$ \\
& 0.025 & & $6.1(2)$ \\
$12 c$ & 0.20 & $8.6(4)$ & $0.55(1)$ \\
& 0.15 & $7.2(2)$ & $0.54(1)$ \\
& 0.10 & $5.2(1)$ & $0.44(1)$ \\
& 0.050 & $3.1(1)$ & $0.42(1)$ \\
& 0.025 & $1.8(1)$ & $0.30(1)$ \\
& $c$ & & $0.28(1)$ \\
$1 a$ & 0.20 & $8.0(3)$ & $1.89(3)$ \\
& 0.15 & $6.0(2)$ & $1.59(5)$ \\
& 0.10 & $4.0(1)$ & $1.35(1)$ \\
& 0.050 & $2.7(1)$ & $1.00(1)$ \\
& 0.025 & $1.4(1)$ & $0.74(1)$ \\
\hline
\end{tabular}

aFor $k_{\mathrm{f}}(i)$ and $k_{\mathrm{d}}(i)$ see Scheme 1 (i refers to the compound under consideration). ${ }^{b}$ Refers to the disappearance of the starting material. ${ }^{\mathrm{C}} \mathrm{At} \mathrm{pH} 7$ adjusted with a triethanolamine buffer.

pounds prevailed, but about $10 \%$ of the starting material decomposed via 3 . This reaction has practically no influence on the shape of the curve referring to the formation of 3 from $1 a$ (Fig. 2), since 3 is formed directly from $1 a$ considerably faster than 14. In addition to nonchromophoric products, $2 a$ yielded 15 . This reaction represents about $20 \%$ of the total disappearance of $2 a$ at $\left[\mathrm{OH}^{-}\right]=0.20 \mathrm{~mol} \mathrm{dm}^{-3}$, becoming more important at lower concentrations of hydroxide ion. However, the route via $2 a$ is too slow, particularly at high alkalinities, to explain quantitatively the formation of 15 from $1 a$. Most probably, 15 is partially formed via an open chain ureido intermediate. Accordingly, the reactions of $1 a$ with aqueous alkalies can be summarized by Scheme 2 . The rate constants for the partial reactions are collected in Table 2 . The reactions of 5-bromo$2^{\prime}, 3^{\prime}$ - $O$-isopropylideneuridine $(5 a)$ were observed to be analogous to those presented for $1 a$. Table 3 records the kinetic data for the reactions depicted in Scheme 3. The rate constants for the decomposition of 5-bromo-5'-O-methyluridine<smiles></smiles>

16<smiles>O=C1NC(=O)N2C(OCC3OC2C(Br)C3O)C1O</smiles>

17
(16) are included in the same table. The disappearance of 16 was not observed to result in any marked accumulation of UV absorbing compounds.

The rate constants for the disappearance of all the 5-bromouridines studied $(1 a, 5 a, 16)$ are linearly related to the concentration of hydroxide

Table 2. The pseudo first-order rate constants for the partial reactions involved in the decomposition of 5bromocytidine (1a) in aqueous sodium hydroxide at $363.2 \mathrm{~K}$.

\begin{tabular}{lllll}
\hline Compd & $\begin{array}{l}{\left[\mathrm{OH}^{-}\right] / \mathrm{mol}} \\
\mathrm{dm}^{-3}\end{array}$ & $\begin{array}{l}k_{\mathrm{f}}(\mathrm{i}) / 10^{-4} \\
\mathrm{~s}^{-1 a}\end{array}$ & $\begin{array}{l}k_{\mathrm{d}}(\mathrm{i}) / 10^{-4} \\
\mathrm{~s}^{-1 a}\end{array}$ & \\
\hline 3 & 0.20 & $0.30(3)$ & $10.3(3)$ & \\
& 0.15 & $0.24(2)$ & $9.0(2)$ & \\
& 0.10 & $0.14(1)$ & $6.9(1)$ & \\
& 0.050 & $0.06(1)$ & $4.1(1)$ & \\
& 0.025 & & $2.0(1)$ & \\
& 0.20 & $0.047(3)$ & $0.70(9)^{b}$ & $0.08(1)^{c}$ \\
& 0.15 & $0.042(2)$ & $0.59(5)$ & $0.07(1)$ \\
& 0.10 & $0.029(3)$ & $0.58(6)$ & $0.07(1)$ \\
& 0.050 & $0.022(1)$ & $0.53(6)$ & $0.05(1)$ \\
& 0.025 & & $0.37(6)$ & $0.04(1)$ \\
$2 a$ & 0.20 & $0.22(2)$ & $1.03(2)^{d}$ & $0.23(2)^{e}$ \\
& 0.15 & $0.15(1)$ & $1.07(4)$ & $0.32(2)$ \\
& 0.10 & $0.10(1)$ & $1.17(5)$ & $0.39(3)$ \\
& 0.050 & $0.049(7)$ & $0.91(4)$ & $0.67(4)$ \\
15 & 0.20 & & $0.076(2)$ & \\
& 0.15 & & $0.069(2)$ & \\
& 0.10 & & $0.050(4)$ & \\
& 0.050 & & $0.027(4)$ & \\
& & & &
\end{tabular}

${ }^{a}$ See Scheme 2. ${ }^{b} k_{\mathrm{d} 1}(14) .{ }^{c} k_{\mathrm{d} 2}(14) .{ }^{d} k_{\mathrm{d} 1}(2 a) .{ }^{e} \boldsymbol{k}_{\mathrm{d} 2}$ (2a). 'Maximal mole fraction of 15 was observed to be 0.05 during the course of the decomposition of $1 a$ in $0.20 \mathrm{~mol} \mathrm{dm}^{-3}$ aqueous sodium hydroxide. 
ion at $\left[\mathrm{OH}^{-}\right] \geq 0.025 \mathrm{~mol} \mathrm{dm}{ }^{-3}$, but the intercepts of the straight lines fall far above the origin. Since the $\mathrm{pK}_{\mathrm{a}}$ value of $1 a$ has been reported ${ }^{5}$ to be 7.4 at $353.2 \mathrm{~K}$, the starting materials may be expected to be present as monoanions under the experimental conditions employed. Accordingly,

Table 3. The pseudo first-order rate constants for the partial reactions involved in the decomposition of 5bromo-2', $3^{\prime}$-O-isopropylideneuridine (5a) and the rate constants for the disappearance of 5-bromo-5' $-O$ methyluridine (16) in aqueous sodium hydroxide at $363.2 \mathrm{~K}$.

\begin{tabular}{|c|c|c|c|c|}
\hline $\begin{array}{l}\text { Com- } \\
\text { pound }\end{array}$ & $\begin{array}{l}{\left[\mathrm{OH}^{-}\right] / \mathrm{mol}} \\
\mathrm{dm}^{-3}\end{array}$ & $\begin{array}{l}k_{f}(\mathrm{i}) / 10^{-4} \\
\mathrm{~s}^{-1 a}\end{array}$ & $\begin{array}{l}k_{\mathrm{d}}(\mathrm{i}) / 10^{-4} \\
\mathrm{~s}^{-1 \mathrm{a}}\end{array}$ & \\
\hline $5 a$ & $\begin{array}{l}0.20 \\
0.15 \\
0.10 \\
0.050 \\
0.025\end{array}$ & & $\begin{array}{c}11.5(1)^{b} \\
10.1(2) \\
8.41(8) \\
6.38(4) \\
4.91(7)\end{array}$ & \\
\hline 7 & $\begin{array}{l}0.20 \\
0.15 \\
0.10 \\
0.050 \\
0.025\end{array}$ & $\begin{array}{l}1.8(2) \\
1.2(1) \\
0.58(5) \\
0.26(2)\end{array}$ & $\begin{array}{l}6.00(14) \\
5.80(11) \\
4.68(8) \\
2.98(5) \\
1.69(4)\end{array}$ & \\
\hline 6 & $\begin{array}{l}0.20 \\
0.15 \\
0.10 \\
0.050 \\
0.025\end{array}$ & $\begin{array}{l}0.82(2) \\
0.72(1) \\
0.39(1) \\
0.19(1)\end{array}$ & $\begin{array}{l}0.81(1)^{c} \\
0.79(1) \\
0.76(1) \\
0.72(1) \\
0.62(1)\end{array}$ & $\begin{array}{l}0.10(1)^{\circ} \\
0.10(1) \\
0.09(1) \\
0.07(1) \\
0.07(1)\end{array}$ \\
\hline $5 d$ & $\begin{array}{l}0.20 \\
0.15 \\
0.10 \\
0.050 \\
0.025\end{array}$ & $\begin{array}{l}0.70(4) \\
0.46(2) \\
0.37(1) \\
0.22(1)\end{array}$ & $\begin{array}{c}4.65(7)^{e} \\
5.31(4) \\
5.81(9) \\
5.75(11) \\
10.9(4)\end{array}$ & $\begin{array}{l}0.95(9)^{f} \\
0.99(8) \\
0.95(8) \\
1.3(1) \\
2.2(2)\end{array}$ \\
\hline 8 & $\begin{array}{l}0.20 \\
0.15 \\
0.10 \\
0.050\end{array}$ & $g$ & $\begin{array}{l}0.13(1) \\
0.12(1) \\
0.097(3) \\
0.057(1)\end{array}$ & \\
\hline 16 & $\begin{array}{l}0.20 \\
0.15 \\
0.10 \\
0.050 \\
0.025\end{array}$ & & $\begin{array}{l}1.47(2)^{h} \\
1.26(1) \\
1.07(1) \\
0.877(12) \\
0.700(7)\end{array}$ & \\
\hline
\end{tabular}

asee Scheme 3. ${ }^{\circ}$ Refers to the disappearance of $5 a$. ${ }^{c} k_{\mathrm{d} 1}(6) .{ }^{d} k_{\mathrm{d} 2}(6) .{ }^{8} k_{\mathrm{d} 1}(5 d) .{ }^{\prime} k_{\mathrm{d} 2}(5 d) .{ }^{g}$ Maximal mole fraction of 8 was observed to be 0.23 during the course of the decomposition of $5 a$ in $0.20 \mathrm{~mol} \mathrm{dm}^{-3}$ aqueous sodium hydroxide. ${ }^{h}$ Refers to the disappearance of 16 .
Table 4. Rate constants for the reactions of hydroxide ion and water with the N3 monoanions of 5bromouridine (1a), and its $2^{\prime}, 3^{\prime}$ - $O$-isopropylidene (5a) and $5^{\prime}-O$-methyl (16) derivatives at $363.2 \mathrm{~K}$.

\begin{tabular}{lll}
\hline $\begin{array}{l}\text { Com- } \\
\text { pound }\end{array}$ & $\begin{array}{l}k\left(\mathrm{OH}^{-}\right) / 10^{-4} \\
\mathrm{dm}^{3} \mathrm{~mol}^{-1} \mathrm{~s}^{-1}\end{array}$ & $\begin{array}{l}k\left(\mathrm{H}_{2} \mathrm{O}\right) / \\
10^{-4} \mathrm{~s}^{-1}\end{array}$ \\
\hline $1 a$ & $6.4(4)$ & $0.65(5)$ \\
$5 a$ & $37(3)$ & $4.4(3)$ \\
16 & $4.2(2)$ & $0.63(3)$ \\
\hline
\end{tabular}

the intercepts may be attributed to the reactions of water with the anionic substrates, or to the kinetically equivalent reactions of hydroxide ion with the neutral substrates. The slopes of the plots give the second-order rate constants for the reactions of hydroxide ion with the substrate monoanions. Table 4 summarizes the results obtained.

Comparison of the rate constants in Table 4 reveals that the $2^{\prime}, 3^{\prime}$ - $O$-isopropylidene group considerably accelerates the decomposition of $1 a$, while the $5^{\prime}-O$-methyl group is slightly rate-retarding. The influences on the rate constants, $k_{\mathrm{f}}(\mathrm{i})$, for the formation of the UV absorbing products, $2 a, 3,14$ and 15 , are comparable. In particular, the formation of the imidazoline and 5',6-anhydro-6-hydroxy derivatives is favoured by the presence of the isopropylidene group. These findings lend support for the previously suggested $^{8}$ cyclic transient intermediate (17), which may subsequently give $2 a, 14$, and an open chain ureido compound leading to 15 . However, the intramolecular attack of the 5'-hydroxyl group on C6 can hardly constitute the main pathway for the alkaline decomposition, since the methylation of this group only moderately retards the disappearance of $1 a$. It is also noteworthy that blocking of the 2 '- and 3 '-hydroxyl functions with an isopropylidene group accelerates not only the reactions via 17 but also the formation of 6-hydroxy uridine (3) which most probably takes place by an intermolecular attack on C6. The reason for this rate enhancement remains obscure. In summary, $2 a, 14$ and 15 appear to be formed via 17, but intermolecular attacks of hydroxide ion on the base moiety are quantitatively more important.

The first-order rate constants, $k_{\mathrm{d}}(\mathrm{i})$, for the decomposition of the UV absorbing compounds 
SUBSTITUTED PYRIMIDINE NUCLEOSIDES

Table 5. ${ }^{13} \mathrm{C}$ NMR chemical shifts and UV absorption maxima for the compounds prepared.

\begin{tabular}{|c|c|c|c|c|c|}
\hline \multirow{2}{*}{$\begin{array}{l}\text { Com- } \\
\text { pound }\end{array}$} & \multicolumn{3}{|c|}{$\delta\left({ }^{13} \mathrm{C}\right)^{a}$} & \multicolumn{2}{|c|}{$\lambda(\max ) / \mathrm{nm}$} \\
\hline & Ribosyl carbons & O'-Alkyl carbons & Base moiety carbons & $\mathrm{pH} 1$ & $\mathrm{pH} 10$ \\
\hline $5 d$ & $61.7,80.6,84.0,86.2,92.1$ & $24.8,26.4,115.2$ & $122,7,132.6,150.0,162.2^{b}$ & $280^{c}$ & $305^{c}$ \\
\hline 8 & $61.7,80.8,83.1,85.6,88.5$ & $24.6,26.2,115.2$ & $114.1,120.7,153.1,166.3$ & $262^{d}$ & $252^{d}$ \\
\hline $12 c$ & $61.9,70.5,75.2,85.2,91.1$ & & $125.0,128.7,155.0,161.3$ & $284^{\theta}$ & 313 \\
\hline 15 & $63.1,71.9,74.8,86.1,87.8$ & & $114.9,122.3,155.1,167.7$ & $262^{\prime}$ & $252^{f}$ \\
\hline 16 & $72.0,73.7,76.8,85.6,92.7$ & 61.6 & $99.1,144.0,153.6,164.6^{g}$ & 279 & 277 \\
\hline
\end{tabular}

${ }^{a}$ Recorded on a Jeol GX-400 spectrometer. Taken as ppm from DSS in $\mathrm{D}_{2} \mathrm{O}$. ${ }^{b}$ For 5-hydroxyuridine in DMSO: 121.7, 133.6, 150.6, 161.7. ${ }^{19}{ }^{c}$ Consistent with the data in Ref. 14. ${ }^{d}$ Consistent with the data for $15 .{ }^{10}{ }^{e} \mathrm{At} \mathrm{pH} 5$. 'Consistent with the data in Ref. 10. ${ }^{9}$ For 5-bromouridine in DMSO: 96.8, 141.4, 150.9, 160.0. ${ }^{19}$

formed are included in Tables 2 and 3. With compounds 3,14 and 15 , and their isopropylidene derivatives 6,7 and $8, k_{\mathrm{d}}(\mathrm{i})$ is initially increased with increasing base concentration and levels off to a constant value when the base moiety becomes deprotonated. On the basis of spectrophotometric measurements, 14,15 and 3 are half ionized at $\left[\mathrm{OH}^{-}\right]=0.006,0.11$ and $0.14 \mathrm{~mol} \mathrm{dm}{ }^{-3}(363.2 \mathrm{~K}$, $I=0.2 \mathrm{~mol} \mathrm{dm}^{-3}$ ), respectively. Most probably, the degradation is initiated by a rate-limiting attack of hydroxide ion on the unionized base moiety of the starting material. The rate constants, $k_{\mathrm{d} 1}(\mathrm{i})$, for the oxidative decomposition of 5 -hydroxyuridines $(2 a, 5 d)$ are initially decreased with increasing alkalinity and then level off to constant values. Evidently, the mono and dianions of the substrates $\left(\mathrm{pK}_{\mathrm{a}} 7.7\right.$ and 11.5 for $5 d$

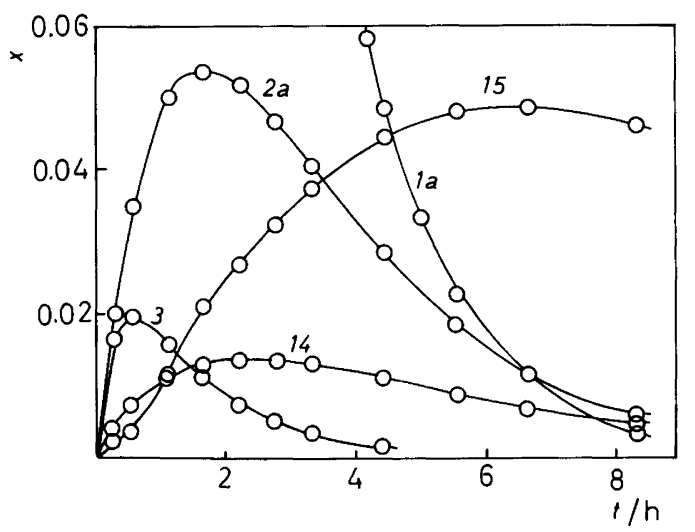

Fig. 2. Time-dependent product distribution for the decomposition of 5-bromouridine (1a) in aqueous sodium hydroxide $\left(0.20 \mathrm{~mol} \mathrm{dm}^{-3}\right)$ at $363.2 \mathrm{~K}$. at $298 \mathrm{~K}^{14}$ ) are both degraged oxidatively, the monoanion being more reactive. The mechanism for the conversion of $2 a$ to 15 and $5 d$ to 8 has been discussed earlier. ${ }^{14}$

\section{Experimental}

Materials. Of the compounds employed in kinetic measurements, 5-bromouridine (1a), 5-hydroxyuridine (2a), 6-hydroxyuridine (3), 5-bromo-2', $3^{\prime}$ - $O$-isopropylideneuridine $(5 a), 5^{\prime}, 6$-anhydro6-hydroxy-2', $3^{\prime}$ - $O$-isopropylideneuridine (6), and 5-bromocytidine (12b) were commercial products of Sigma Chemical Company. They were used as received after checking their purity by LC. The other nucleosides were prepared by conventional methods and purified chromatographically on a reversed phase column (Spherisorb, $250 \times 8 \mathrm{~mm}, 5 \mu \mathrm{m}$ ) using aqueous acetonitrile as eluant. Accordingly, 5-hydroxy-2',3'-Oisopropylideneuridine $(5 d)$ was obtained by refluxing $5 a$ in aqueous sodium bicarbonate saturated with carbon dioxide. ${ }^{14}$ Refluxing of $5 a$ and $1 a$ in unbuffered aqueous alkali gave the imidazoline nucleosides 8 and 15 , respectively; ${ }^{14} 6$-hydroxy-2', $3^{\prime}$ - $O$-isopropylideneuridine (7) was prepared by treating 3 with acetone in the presence of $p$-toluenesulfonic acid. The conditions employed were similar to those described for the synthesis of $2^{\prime}, 3^{\prime}-O$-isopropylideneuridine. ${ }^{15}$ The synthesis of 5-hydroxycytidine (12c) was accomplished by applying the method of Vorbrüggen. ${ }^{16}$

Of the starting materials employed, 1- $O$ acetyl-2,3,5-tri- $O$-benzoyl- $\beta$-D-ribofuranose was a commercial product (Sigma) and 5-hydroxycytosine was obtained by oxidizing cytosine 


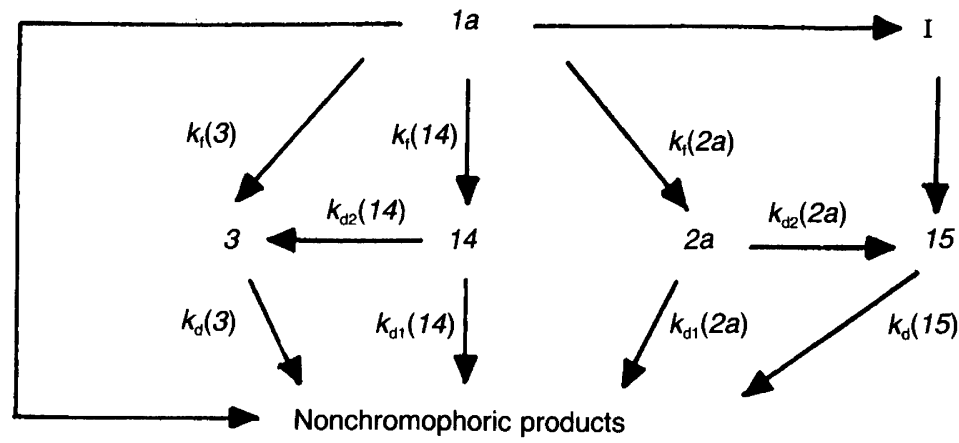

(Sigma) with potassium peroxodisulfate. ${ }^{17}$ By hydrolyzing 6 in aqueous ethanol containing hydrogen chloride, 5', 6-anhydro-6-hydroxyuridine (14) was obtained. The reaction was stopped when the concentration of 14 reached maximum and the product mixture was fractionated on a reversed phase column. By treating $5^{\prime}$ - $O$-methyluridine $^{18}$ with bromine in an aqueous solution, 5bromo-5'-O-methyluridine (16) was synthesized. The products were characterized by ${ }^{13} \mathrm{C}$ NMR and UV spectroscopy. The data observed are given in Table 5.

Kinetic measurements. The LC method described previously ${ }^{20}$ was applied to follow the progress of the reactions. The separations were carried out on a LiChrosorb RP- 18 column $(250 \times 4 \mathrm{~mm}, 10$ $\mu \mathrm{m})$ using mixtures of acetonitrile and acetic acid buffer ( $\mathrm{pH} \mathrm{4.3)}$ as eluant. With unprotected nucleosides, the proportion of acetonitrile was $3 \%$ (v/v); with $O^{\prime}$ alkylated compounds, $16 \%$. The initial substrate concentrations in kinetic runs were of the order of $10^{-3} \mathrm{~mol} \mathrm{dm}^{-3}$. The products were identified by comparing their retention times and UV spectra with those of authentic samples. The peak heights were transformed to concentrations with the aid of calibration solutions of known concentrations.

Spectrophotometric measurements. The equilibrium constants for the ionization of compounds 3,14 and 15 were determined as described previously. ${ }^{21}$

Calculation of the rate constants. The pseudo first-order rate constants, $k_{\mathrm{f}}(\mathrm{i})$, for the formation of compound $i$ during the decomposition of compound $\mathrm{j}$ were calculated by eqn. (1), where $k_{\mathrm{d}}(\mathrm{i})$ and $k_{\mathrm{d}}(\mathrm{j})$ are the pseudo first-order rate constants for the disappearance of $\mathrm{i}$ and $\mathrm{j}$, respectively, $[\mathrm{i}]_{t}$ is the concentration of $\mathrm{i}$ at moment $t$, and $[\mathrm{j}]_{\mathrm{o}}$ is the initial concentration of the starting material $j$. The rate constants $k_{\mathrm{d}}(\mathrm{i})$ were determined separately for all the compounds studied using the integrated first-order rate equation.

$k_{\mathrm{f}}(\mathrm{i})=\frac{k_{\mathrm{d}}(\mathrm{j})-k_{\mathrm{d}}(\mathrm{i})}{\mathrm{e}^{-k_{\mathrm{d}}(\mathrm{i}) t}-\mathrm{e}^{-k_{\mathrm{d}}(\mathrm{j}) t}} \times \frac{[\mathrm{i}]_{t}}{[\mathrm{j}]_{\mathrm{o}}}$

Scheme 3.

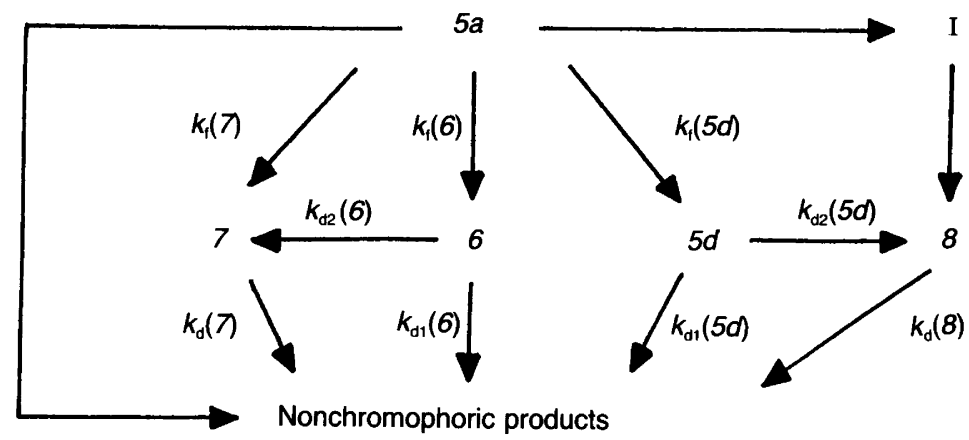


Acknowledgement. The financial aid from the Academy of Finland, Council for the Natural Sciences, is gratefully acknowledged.

\section{References}

1. Part XIX of the series Mechanisms for the Solvolytic Decompositions of Nucleoside Analogues.

2. Kaufman, H. E., Martola, E. L. and Dohlman, C. Arch. Ophthalmol. 68 (1962) 235.

3. Prusoff, W. H. Pharmacol. Rev. 19 (1967) 209.

4. Cohen, S. S. Prog. Nucl. Acid Res. Mol. Biol. 5 (1966) 1 .

5. Garrett, E. R. and Yakatan, G. J. J. Pharm. Sci. 57 (1968) 1478.

6. Garrett, E. R., Chemburkar, P. B. and Suzuki, T. Chem. Pharm. Bull. 13 (1965) 1113.

7. Otter, B. A., Falco, E. A. and Fox, J. J. Tetrahedron Lett. (1968) 2967.

8. Otter, B. A., Falco, E. A. and Fox, J. J. J. Org. Chem. 34 (1969) 1390.

9. Fox, J. J., Miller, N. C. and Cushley, R. J. Tetrahedron Lett. (1966) 4927.

10. Otter, B. A. and Fox, J. J. J. Am. Chem. Soc. 89 (1967) 3663.
11. Otter, B. A., Falco, E. A. and Fox, J. J. J. Org. Chem. 33 (1968) 3593.

12. Kikugawa, K., Kawada, I. and Ichino, M. Chem. Pharm. Bull. 23 (1975) 35.

13. Lönnberg, H., Käppi, R., Suokas, P. and Darzynkiewicz, E. Acta Chem. Scand. B. In press.

14. Otter, B. A., Falco, E. A. and Fox, J. J. J. Org. Chem. 34 (1969) 2636.

15. Tomasz, J. In: Townsend, L. B. and Tipson, R. S., Ed. Nucleic Acid Chemistry, John Wiley \& Sons, 1978, p. 765.

16. Vorbrüggen, H., Krolikiewicz, K. and Bennua, B. Chem. Ber. 114 (1981) 1234.

17. Moschel, R. C. and Behrman, E. J. J. Org. Chem. 39 (1974) 1983.

18. Kusmierek, J. T., Giziewicz, J. and Shugar, D. Biochemistry 12 (1973) 194.

19. Stothers, J. B. Carbon-13 NMR Spectroscopy, Academic Press, New York 1972.

20. Lönnberg, H. and Lehikoinen, P. J. Org. Chem. 49 (1984) 4964.

21. Lehikoinen, P. and Lönnberg, H. Chem. Scr. 26 (1986) 103.

Received June 2, 1986. 